\title{
Wave energy and the upper depth limit distribution of Posidonia oceanica
}

\section{Eduardo Infantes*, Jorge Terrados, Alejandro Orfila, Bartomeu Cañellas and Amaya Álvarez-Ellacuria}

Instituto Mediterráneo de Estudios Avanzados, IMEDEA (CSIC-UIB), Miquel Marqués 21, 07190, Esporles,

Spain, e-mail: eduardo.infantes@uib.es

* Corresponding author

\begin{abstract}
It is widely accepted that light availability sets the lower limit of seagrass bathymetric distribution, while the upper limit depends on the level of disturbance by currents and waves. The establishment of light requirements for seagrass growth has been a major focus of research in marine ecology, and different quantitative models provide predictions for seagrass lower depth limits. In contrast, the influence of energy levels on the establishment, growth, and maintenance of seagrasses has received less attention, and to date there are no quantitative models predicting the evolution of seagrasses as a function of hydrodynamics at a large scale level. Hence, it is not possible to predict either the upper depth limit of the distribution of seagrasses or the effects that different energy regimes will have on these limits. The aim of this work is to provide a comprehensible methodology for obtaining quantitative knowledge and predictive capacity for estimating the upper depth limit of seagrasses as a response to wave energy dissipated on the seafloor. The methodology has been applied using wave data from 1958 to 2001 in order to obtain the mean wave climate in deep water seaward from an open sandy beach in the Balearic Islands, western Mediterranean Sea where the seagrass Posidonia oceanica forms an extensive meadow. Mean wave conditions were propagated to the shore using a two-dimensional parabolic model over the detailed bathymetry. The resulting hydrodynamics were correlated with bottom type and the distribution of $P$. oceanica. Results showed a predicted near-bottom orbital velocity of between 38 and $42 \mathrm{~cm} \mathrm{~s}^{-1}$ as a determinant of the upper depth limit of $P$. oceanica. This work shows the importance of interdisciplinary effort in ecological modeling and, in particular, the need for hydrodynamical studies to elucidate the distribution of seagrasses in shallow depths. Moreover, the use of predictive models would permit evaluation of the effects of coastal activities (construction of ports, artificial reefs, beach nutrientinput, dredging) on benthic ecosystems.
\end{abstract}

Keywords: near-bottom orbital velocity; parabolic model; Posidonia oceanica upper depth limit; seagrass distribution; wave energy.

\section{Introduction}

Seagrasses are marine flowering plants that cover large areas in shallow coastal waters; the meadows they form are among the most biologically diverse and productive components of coastal systems. Posidonia oceanica (L.) Delile, an endemic seagrass species of the Mediterranean Sea, grows between the depths of 0.5 and $45 \mathrm{~m}$ (Procaccini et al. 2003) and covers an estimated surface area between 2.5 and 5 million ha, approximately $1-2 \%$ of the 0-50 m depth zone (Pasqualini et al. 1998).

The study of light requirements for seagrass growth has been a major focus of research in marine ecology, and different quantitative models provide predictions of the seagrass lower depth limits (Dennison and Alberte 1985, Dennison 1987, Duarte 1991, Kenworthy and Fonseca 1996, Koch and Beer 1996, Greve and Krause-Jensen 2005). Seagrasses can thrive up to depths where the irradiance at the top of the leaf canopy is above $11 \%$ of surface irradiance (Duarte 1991), or where the number of hours with values of irradiance above photosynthetic saturation is $>6-8 \mathrm{~h}$ (Dennison and Alberte 1985). The upper depth limit of distribution of seagrasses has been related to their tolerance of desiccation at low tide (Koch and Beer 1996) and to ice scour (Robertson and Mann 1984). In seas with low tidal range and no ice formation, such as the Mediterranean Sea, the upper depth limit of seagrasses is determined mainly by their tolerance of wave energy (Koch et al. 2006). However, quantitative estimates of the wave energy that sets the upper depth limit of seagrasses are still scarce to date.

Studies in flumes have evaluated the influence of seagrass on unidirectional water flow (Fonseca et al. 1982, Gambi et al. 1990, Folkard 2005), sediment stabilization (Fonseca and Fisher 1986), and wave attenuation (Fonseca and Cahalan 1992). Field measurements and experiments have also been performed to study water flow in seagrass meadows (Fonseca 1986, Worcester 1995, Koch and Gust 1999) and evaluate their effect on particle resuspension (Terrados and Duarte 2000, Gacia and Duarte 2001). However, few studies have analyzed the effects of local hydrodynamics on seagrasses.

Storms can resuspend sediments and uproot seagrasses, whereas sediment deposition can bury them and cause mortality (Williams 1988, Preen et al. 1995, Duarte et al. 1997, Bell et al. 1999). Conceptual models have been proposed to explain differences in shape, bottom relief, and cover of seagrass meadows (Fonseca et al. 1983, Fonseca and Kenworthy 1987) or the depth distribution of intertidal seagrass (van Katwijk et al. 2000) as a function of wave energy and/or current velocity. Local hydrodynamics (indirectly estimated from the weight loss of clod cards) have been related to depth and seagrass presence and have been used to identify the habitat requirements of South Australian seagrass species 
(Shepherd and Womersley 1981). Keddy (1984) developed a relative wave exposure index (REI) in order to quantify the degree of wave exposure by using wind speed, direction, and fetch measurements. REI values have been correlated to different attributes of seagrass meadows, such as the content of silt-clay and organic matter of the sediment, seagrass cover, shoot density (Fonseca and Bell 1998, Fonseca et al. 2002, KrauseJensen et al. 2003, Frederiksen et al. 2004), and biomass (Hovel et al. 2002). Shallow seagrass populations tend to be more spatially fragmented in wave-exposed environments than in wave-sheltered environments (Fonseca and Bell 1998, Frederiksen et al. 2004), and temporal changes in seagrass cover are also greater at the most wave-exposed sites (Frederiksen et al. 2004). Plaster clod cards and REI provide only semi-quantitative idiosyncratic estimates of current and/or wave energy and, therefore, comparison between studies is difficult. Additionally, REI estimates do not consider the influence of depth on wave damping (but see van Katwijk and Hermus 2000). Direct quantitative measurements of the energy of waves and currents impinging on seagrasses are necessary to elucidate their effects on them, to identify their habitat requirements, to predict their spatial distribution and their response to both natural (i.e., storms, hurricanes, etc.) and anthropogenic (i.e., dredging and beach eutrophication, coastal development, etc.) disturbances.

The main goal of this study was to develop a methodology to estimate the wave energy impinging on seagrass meadows (Figure 1) and to obtain a quantitative and testable relationship between wave energy and the upper depth limit of the Mediterranean seagrass Posidonia oceanica. Wave energy estimation was obtained by analyzing 44 years of wave data. We consider long-term historical wave data, rather than present-day wave measurements, are more appropriate to link wave energy to the presence of $P$. oceanica, given the low rates of vegetative growth and space occupancy in this seagrass species (Marbà and Duarte 1998). Aerial color photographs and bathymetric data were also used for an accurate mapping of the meadow and to delimit the upper

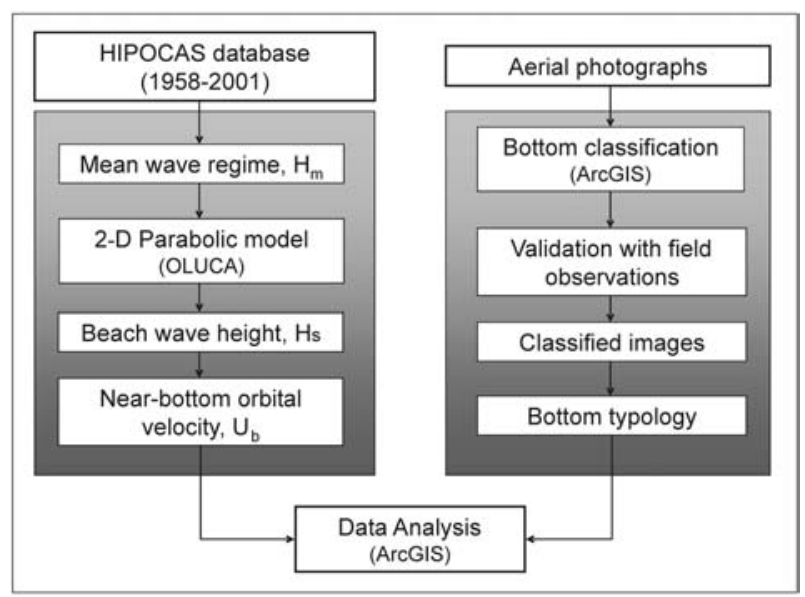

Figure 1 Schematic diagram of the approach presented. HIPOCAS, hindcast of dynamic processes of the ocean and coastal areas of Europe. depth boundary of $P$. oceanica. We provide a testable estimate of the near-bottom current velocity that could set a threshold for the presence of $P$. oceanica and, therefore, determine the upper depth limit of this seagrass.

\section{Materials and methods}

\section{Study areas and regional settings}

This work was carried out in Cala Millor, located on the northeast coast of Majorca Island (Figure 2A,B). The beach is in an open bay with an area of ca. $14 \mathrm{~km}^{2}$. Near the coast to $8 \mathrm{~m}$ depth, there is a regular slope indented with sand bars near the shore (Figure $2 \mathrm{C}$ ); these bars migrate from offshore to onshore between periods of gentle wave conditions. At depths from $6 \mathrm{~m}$ to $35 \mathrm{~m}$, the seabed is covered by a meadow of Posidonia oceanica. This area was chosen for this study because of the availability of data from previous studies. The tidal regime is microtidal, with a spring range of less than $0.25 \mathrm{~m}$ (Gómez-Pujol et al. 2007). The bay is located on the east coast of the island of Majorca and it is therefore exposed to incoming wind and waves from NE to ESE directions. According to the criteria of Wright and Short (1983), Cala Millor is an intermediate barred sandy beach formed by biogenic sediments with median grain values ranging between 0.28 and $0.38 \mathrm{~mm}$ at the beach front (L. GómezPujol and A. Orfila, unpublished data).

\section{HIPOCAS database (1958-2001) and deep water wave characterization}

Wave data used are part of the Hindcast of Dynamic Processes of the Ocean and Coastal Areas of Europe (HIPOCAS) project. This database consists of a high resolution, spatial and temporal, long-term hindcast dataset (Soares et al. 2002, Ratsimandresy et al. 2008). The HIPOCAS data were collected hourly for the period 1958 to 2001, providing 44 years of wave data with a $0.125^{\circ}$ spatial resolution; this is the most complete wave data base currently available for the Mediterranean Sea. These hindcast models have become powerful tools, not only for engineering or predictive purposes, but also for long-term climate studies (Cañellas et al. 2007). These data were produced by the Spanish Harbor Authority by dynamical downscaling from the National Center for Environmental Prediction (NCEP) and the National Center for Atmospheric Research (NCAR) global reanalysis using the regional atmospheric model REMO. We used the data from HIPOCAS node 1433 (see Figure 2B) located $10 \mathrm{~km}$ offshore at $50 \mathrm{~m}$ depth, which is the closest HIPOCAS node to Cala Millor. The long-term distribution of significant wave height and wave direction at this node (Figure 3) shows that the most energetic waves usually come from N-NNE. These wave directions are also the most frequent during the 44-year dataset.

Data contained in the HIPOCAS node consist of a set of sea states (one per hour) defined by their significant wave height, spectral peak period, and direction. An estimation of the long-term distribution of the mean significant wave height $\left(\mathrm{H}_{\mathrm{m}}\right)$ and its standard deviation was 

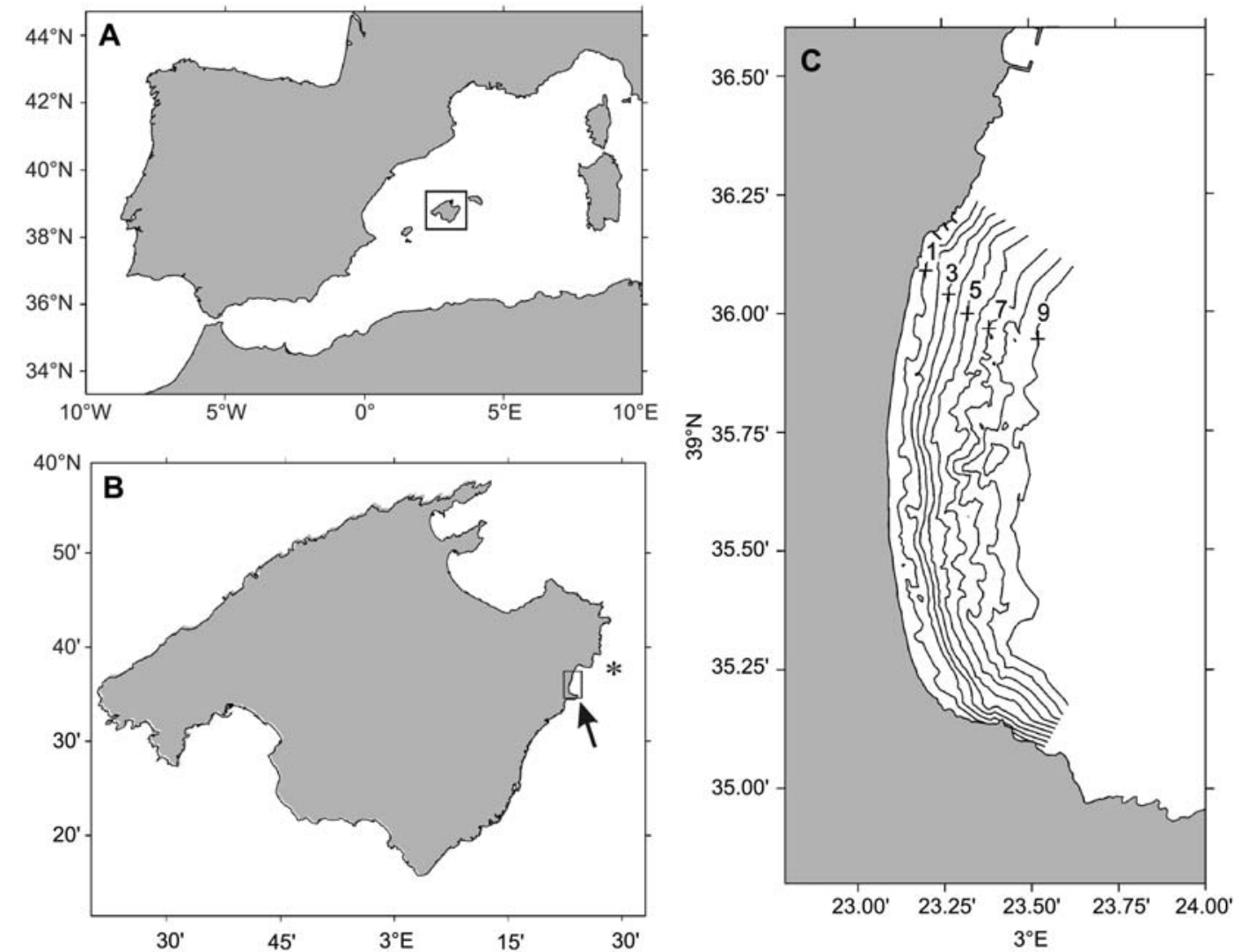

Figure 2 (A) Location of Majorca in the Mediterranean Sea. (B) Location of the study area of Cala Millor in Majorca. The asterisk (*) indicates HIPOCAS node 1433. (C) Bathymetry of Cala Millor with isobaths (in meters).

carried out making use of the lognormal probability distribution (Castillo et al. 2005). The long-term probability distribution identifies the most probable sea state for the 44-year period. Before estimation of this wave regime, data were pre-selected taking into account their incoming directions. Only sea states directed towards the beach were included in the analysis. Mean wave climate for Hipocas node 1433 provides an $H_{m}$ value of $1.53 \pm 0.96( \pm 1 \mathrm{SD}) \mathrm{m}$, a peak period of $7.3 \mathrm{~s}$, and a direction of $11.25^{\circ}$. This mean (most probable) wave cli-

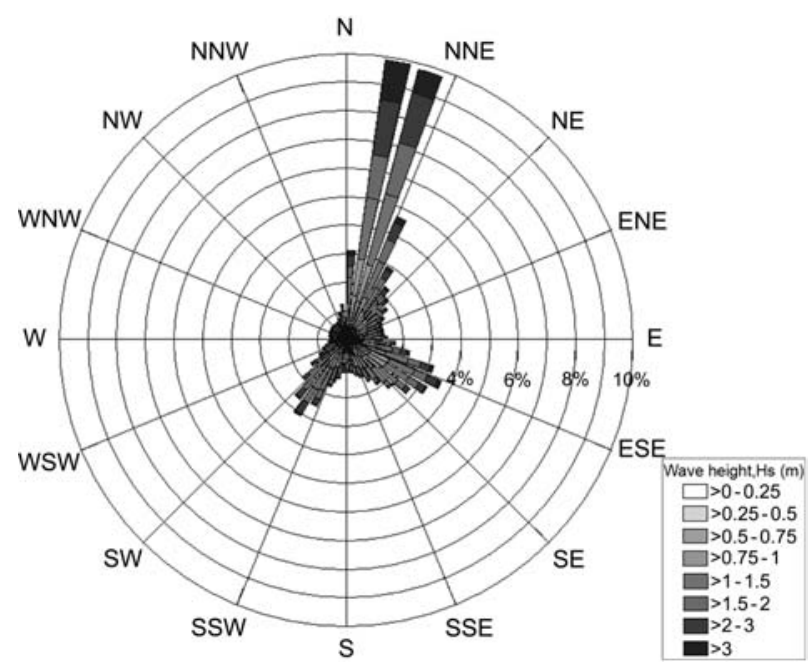

Figure 3 Directional wave histogram for HIPOCAS node 1433 (50 km from Cala Millor). mate was propagated to the shore using a parabolic model.

\section{Shallow-water wave conditions}

As water waves propagate from the region where they are generated to the coast, both wave amplitude and wavelength are modified. The surf zone is a highly dynamic area where energy from waves is partially dissipated through turbulence in the boundary layer and transformed into short and long waves, mean sea level variations, and currents (Dean and Dalrymple 2002). In the present work, waves were propagated using a gentle slope parabolic model (OLUCA-MC), which includes refraction-diffraction effects as well as energy losses due to wave breaking (Kirby and Dalrymple 1983, GIOC 2003). Detailed bathymetry obtained with echo-sounding was used to generate the numerical mesh. The model solves continuity and momentum equations assuming a smooth bottom (e.g., variations of the bottom negligible within a wave length) and converting the hyperbolic system to a parabolic system (e.g., with wave propagation in one direction).

Two grids were generated: the external grid $(122 \times 81$ nodes), which covers the deeper area with $75 \mathrm{~m}$ resolution between nodes, and the internal grid $(140 \times 311$ nodes), which covers the shallow area with $15 \mathrm{~m}$ resolution. The model output provides the wave field (significant wave height and direction of the mean flux energy) in the whole grid. 
Maximum near-bottom orbital amplitudes $\left(A_{b}\right)$ were calculated following the linear wave theory:

$A_{b}=\frac{H s}{2 \sinh (2 \pi D / \lambda)}$

where $D$ is the water depth and $\lambda$ is the wave length calculated iteratively as:

$\lambda=\frac{T_{p}^{2} g}{2 \pi} \tanh \left(\frac{2 \pi D}{\lambda}\right)$

where $T_{p}$ is the peak period and $g$ is the acceleration of gravity. The maximum near-bottom orbital velocity $\left(U_{b}\right)$ is:

$U_{b}=2 \pi A_{b} / T_{p}$

\section{Bottom typology and bathymetry}

Remote sensing of the seabed from air or space is commonly used for mapping seagrass habitats over a wide range of spatial scales (McKenzie et al. 2001). Satellite spectral images from Ikonos are suitable for the detection and mapping of the upper depth limit of seagrass distribution in shallow clear waters (Fornes et al. 2006). Aerial color photographs have been used in some studies to describe temporal changes in the distribution of seagrasses (Hine et al. 1987), to evaluate the effect of wave exposure (Frederiksen et al. 2004), and the influence of anthropogenic activities (Leriche et al. 2006). We used aerial photographs for mapping the area covered by Posidonia oceanica, dead $P$. oceanica rhizome, rocks, and sand up to $11 \mathrm{~m}$ depth. Aerial color photographs were taken in August of 2002 with a resolution of $0.4 \mathrm{~m}$. Polygons were drawn around the different areas with Arc/GIS software (Arc/Info and Arc/Map v9.0, ESRI) and classified by bottom types. In those areas where bottom recognition was not possible from the aerial photographs, field surveys were carried out to identify the typology of the substratum (some areas tend to accumulate seagrass leaves which can lead to false interpretation of aerial images). Image classification was validated with bathymetric filtered echo-soundings and field observations.

During 2005, an acoustic survey was carried out to determine the bathymetry of the inner mesh and to test the classification of the seagrass coverage from the aerial photographs. Acoustic mapping of Posidonia oceanica was performed with a ship-mounted Biosonics DE-4000 echo sounder (BioSonics, Inc., Seattle, USA) equipped with a $200 \mathrm{KHz}$ transducer. The draught of the boat allowed sampling up to depths of approximately $0.5 \mathrm{~m}$. Inshore-offshore echo-sounding transects were sampled perpendicularly to the bathymetric gradient, with a separation of $50 \mathrm{~m}$ between transects. Acoustic pulse rate was set to $25 \mathrm{~s}^{-1}$ and the sampling speed was set to 3 knots, which allowed for a horizontal resolution of $1 \mathrm{~m}$ (Orfila et al. 2005). Bottom typology was estimated as the most probable after echogram examination using the first to second bottom echo ratio technique (Orlowski 1984, Chivers et al. 1990). The resulting echo sounding points were filtered, averaged ( 1 output equals 20 pings) and clustered into three groups ( $P$. oceanica meadows, sandy, and hard bottoms) taking into consideration calibrations performed for previously classified bottoms. Hard bottoms include rocks, $P$. oceanica rhizome mats, and zones with poor seagrass coverage (Figure 4). Afterwards, this map was verified by direct observation at random points, also distinguishing those bottom types that the algorithm was not able to identify (i.e., dead rhizome and rocks). The map of bottom typology in Figure 4 represents the final classification (aerial photograph verified with echo-sounding and direct SCUBA observations).

Bathymetric data were interpolated using the kriging technique to create 1-m scale depth contours that were overlaid with bottom typology. Similarly, maximum nearbottom orbital velocity data were interpolated to create 5-cm s ${ }^{-1}$ scale $U_{b}$ contours that were overlaid with bottom typology. Percent coverage of rocks, sand, dead rhizomes of Posidonia oceanica, and P. oceanica were calculated for each depth and near-bottom orbital velocity interval. A total of 400 points were randomly selected throughout the study area, and the corresponding bottom type and near-bottom orbital velocity interval were used to calculate the average near-bottom orbital velocity for each bottom type. Additionally, 400 points along the upper limit of the $P$. oceanica meadow were randomly selected and the corresponding near-bottom orbital velocities were used to estimate an average along that edge. Differences in near-bottom orbital velocity between each bottom type and the upper limit of $P$. oceanica were evaluated using Kruskal-Wallis non-parametric analysis of variance (due to heterogeneity of data variance).

\section{Results}

The study site has a total area of 121.44 ha wherein sand and Posidonia oceanica meadow are the most abundant substrata. Shallow bottoms in Cala Millor (depths between 0 and $6 \mathrm{~m}$ ) are mostly sandy, with some patches of rock, particularly in the center and south parts of the beach (Table 1). The upper depth limit of $P$. oceanica is located between 5 and $6 \mathrm{~m}$ and the meadow continues down to 30-35 $\mathrm{m}$ depth (acoustic survey data not shown). The limit between seagrass and sand is irregular and has several areas of hard substratum between 4 and $7 \mathrm{~m}$ that correspond to dead rhizomes of $P$. oceanica partly covered by sand and algae, which can be indicative of meadow regression (Figure 4). $P$. oceanica reaches the highest percentage cover at depths greater than $8 \mathrm{~m}$, and no stands are found in depths shallower than $4 \mathrm{~m}$. Most of the rocky bottom is in the shallowest water, between 0 and $2 \mathrm{~m}$. Two large sand fingers cross the seagrass meadow at the center of the study area; these may have resulted from sand transport from the exposed beach after storm events.

Mean wave conditions propagated over the beach resulted in wave heights between 0.2 and $0.4 \mathrm{~m}$, with significant wave breaking in the shallow sandy area (between 0.5 and $1 \mathrm{~m}$ ) (Figure 5A) and near-bottom orbital velocities up to $110 \mathrm{~cm} \mathrm{~s}^{-1}$. The highest velocities occurred in the shallow sandy part of the beach (between 1 and $3 \mathrm{~m}$ ) (Figure 5B). 


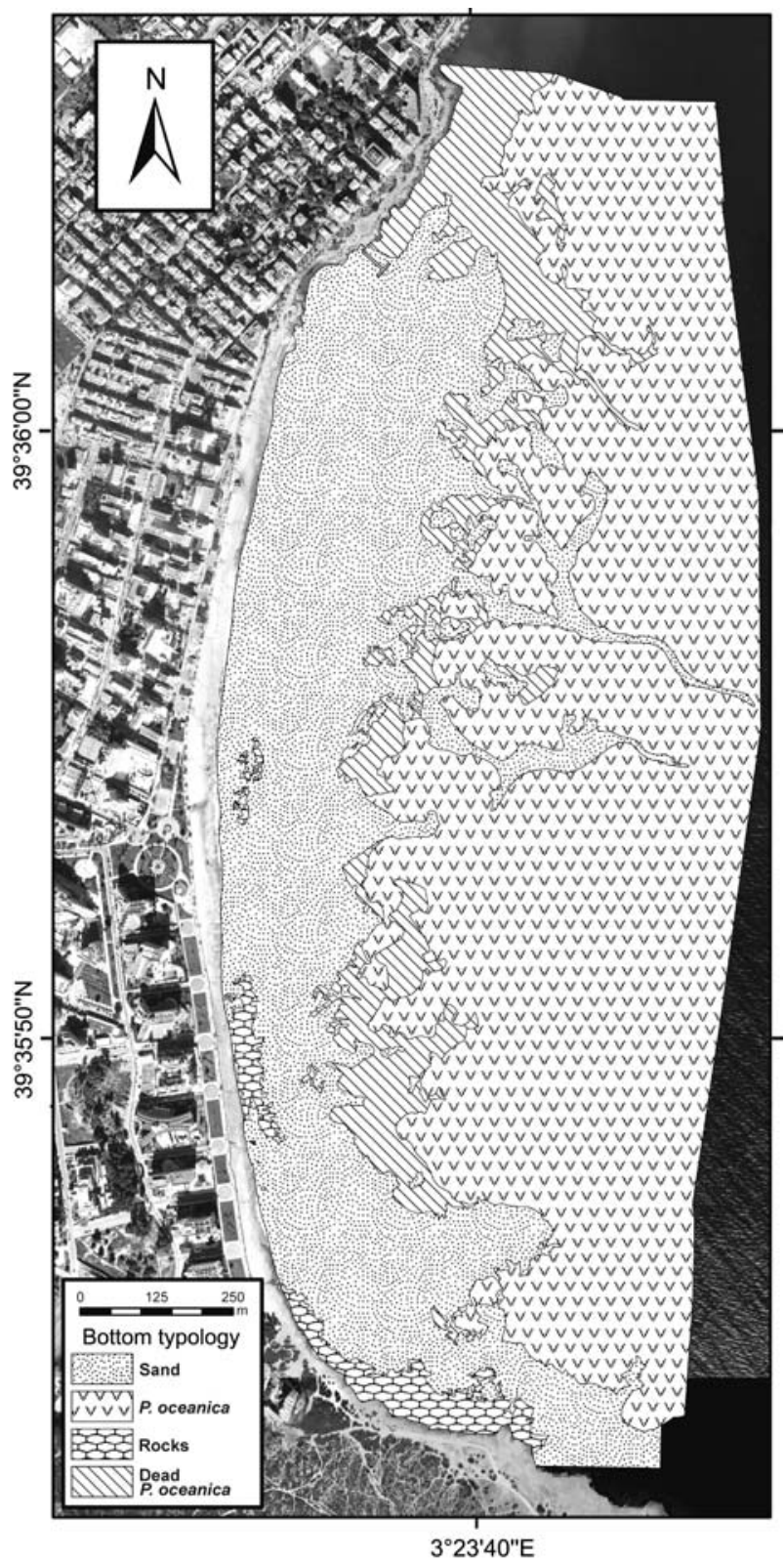

Figure 4 Bottom typology off Cala Millor (Majorca, western Mediterranean Sea). P., Posidonia.

Sandy areas are associated with high values of nearbottom orbital velocities, while Posidonia oceanica is associated with lower velocities (Figure 6). P. oceanica is not present in areas with velocities higher than $38-42 \mathrm{~cm}$ $\mathrm{s}^{-1}$. This velocity interval might be considered a first estimate of the threshold near-bottom orbital velocity that allows the $P$. oceanica to occur in Cala Millor.

Variance of near-bottom orbital velocity was higher in sand, rock, and dead Posidonia oceanica than in the $P$. oceanica meadow (Figure 7). Kruskal-Wallis non-parametric analysis of variance detected significant differences in the average near-bottom orbital velocity between bottom types $[\mathrm{H}(4, \mathrm{n}=800)=310.34, \mathrm{p}<0.001]$, and post hoc multiple comparisons of mean ranks showed that velocities were lower in $P$. oceanica stands and at the $P$. oceanica upper limit than in rock, sand, and dead $P$. oceanica (Figure 7).

\section{Discussion}

In this study, we present a methodology to estimate the wave energy that determines the upper depth limit of Posidonia oceanica. Our data show that an increase in wave energy is related to a decrease of $P$. oceanica cover, and that above a threshold level of wave energy seagrass is not present. It is important to emphasize that the evidence provided in this study is correlative and applies to our study site only. Other locations, with different sediment characteristics and wave climates might provide different threshold values. Additional sources of disturbance (both natural and anthropogenic) will also introduce variability in the threshold estimates. The near-bottom orbital velocities are computed from numerical model predictions and real velocities within the meadow could be lower due to wave attenuation by the seagrass meadow and wave-current interactions. However, the predicted velocities where $P$. oceanica is not present provide an estimate of the threshold velocities that would impede the persistence of this seagrass species.

The usefulness of this methodology is that it provides quantitative estimates of wave energy that sets the upper depth limit of Posidonia oceanica and, therefore, these can be compared to those obtained in other locations.

We obtained an estimate of the threshold value of nearbottom orbital velocity that allows the long-term persistence of Posidonia oceanica (38-42 $\mathrm{cm} \mathrm{s}^{-1}$ ). It has been suggested that Zostera marina L. can tolerate unidirec-

Table 1 Percent cover of bottom type at different depths.

\begin{tabular}{lllcc}
\hline Depth $(\mathrm{m})$ & $\begin{array}{l}\text { Posidonia } \\
\text { oceanica }\end{array}$ & Sand & $\begin{array}{c}\text { Rock } \\
\text { oceanica }\end{array}$ \\
\hline $1-2$ & 0 & 96.63 & 3.24 & 0.13 \\
$2-3$ & 0 & 97.73 & 0 & 0.52 \\
$3-4$ & 0 & 97.31 & 0 & 2.69 \\
$4-5$ & 0.46 & 83.36 & 0 & 0 \\
$5-6$ & 11.55 & 51.03 & 0 & 37.42 \\
$6-7$ & 42.34 & 25.27 & 0 & 32.39 \\
$7-8$ & 73.87 & 21.10 & 0 & 5.03 \\
$8-9$ & 83.82 & 14.64 & 0 & 0 \\
$9-10$ & 94.40 & 5.59 & 2.02 & 0 \\
$10-11$ & 97.98 & $528,241.5$ & $25,192.7$ \\
Total area $\left(\mathrm{m}^{2}\right)$ & $565,349.42$ & $95,632.92$ & 0 \\
\hline
\end{tabular}

Total area of coverage of each bottom type is presented in the last row. 

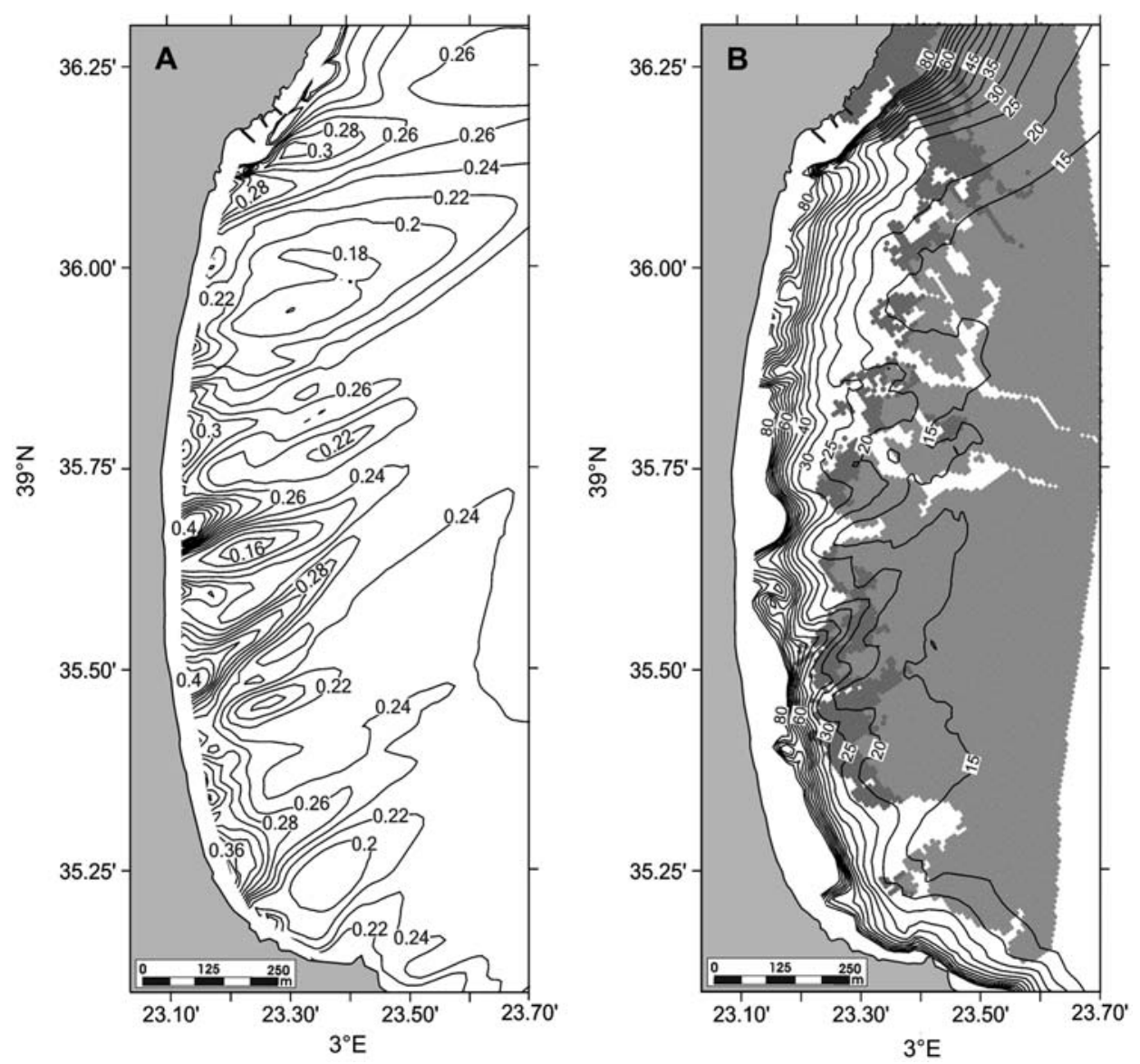

Figure 5 (A) Distribution of wave heights $(m)$ at the beach derived from mean wave conditions $\left(11.25^{\circ}, H_{m}=1.53 \mathrm{~m}, T_{p}=7.30 \mathrm{~s}\right)$. (B) Distribution of near-bottom orbital velocities $\left(\mathrm{U}_{\mathrm{b}}, \mathrm{m} \mathrm{s}^{-1}\right)$ at the beach and cover of the Posidonia oceanica meadow (gray) and dead rhizomes (dark gray).

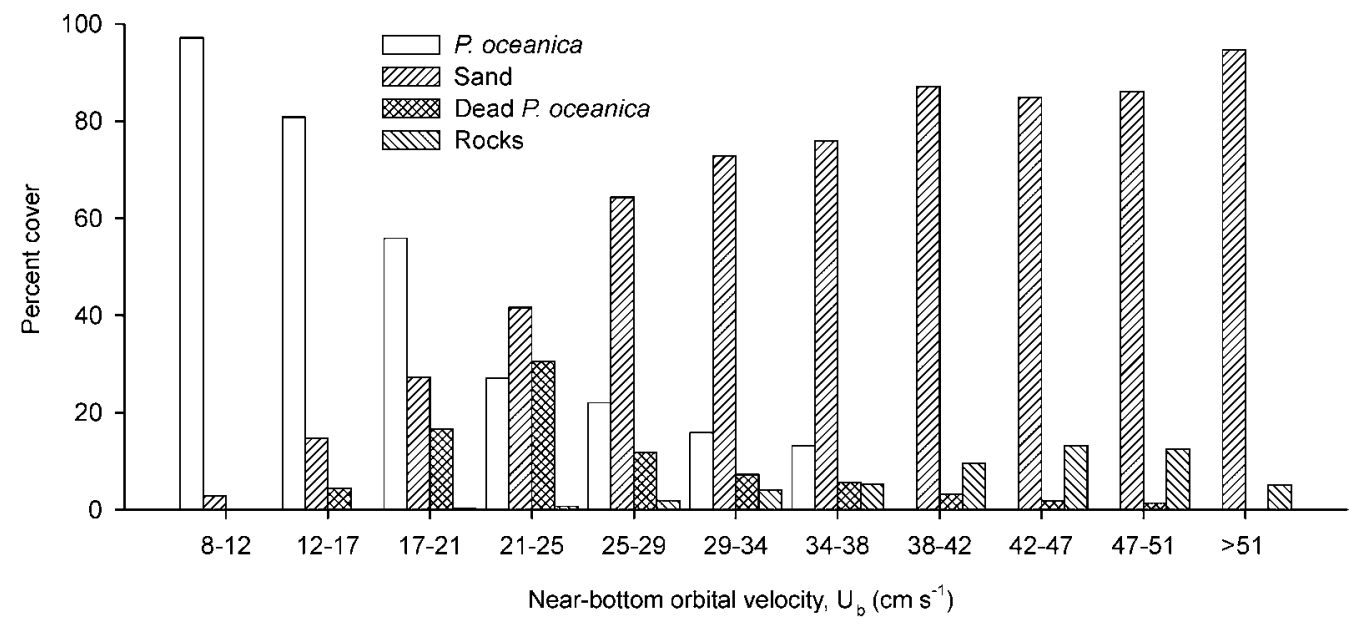

Figure 6 Percent coverage of the different bottom types in each of the near-bottom orbital velocity $\left(U_{b}\right)$ intervals established in Cala Millor (Majorca, Western Mediterranean Sea). P., Posidonia.

tional current velocities up to $120-150 \mathrm{~cm} \mathrm{~s}^{-1}$ and that the meadows formed by this species become spatially fragmented at tidal current velocities of $53 \mathrm{~cm} \mathrm{~s}^{-1}$ (Fonseca et al. 1983). Shallow mixed meadows of $Z$. marina and Halodule wrightii Asch. seem to remain spatially fragmented at tidal current speeds above $25 \mathrm{~cm} \mathrm{~s}^{-1}$ (Fonseca and Bell 1998). Experimental transplantations of $Z$. marina along depth gradients in intertidal zones indicate that this species cannot persist at sites where the maximum bottom orbital velocity during the tidal cycle reaches 53-63 $\mathrm{cm} \mathrm{s}^{-1}$. Furthermore, this species can survive when exposed to waves for less than $60 \%$ of the time and maximum orbital velocity is less than $40 \mathrm{~cm} \mathrm{~s}^{-1}$ (van Katwijk and Harmus 2000). Hence, our estimate of the threshold value of near-bottom orbital velocity that allows the persistence of $P$. oceanica is within the range of values of current velocity proposed for other seagrass species. 


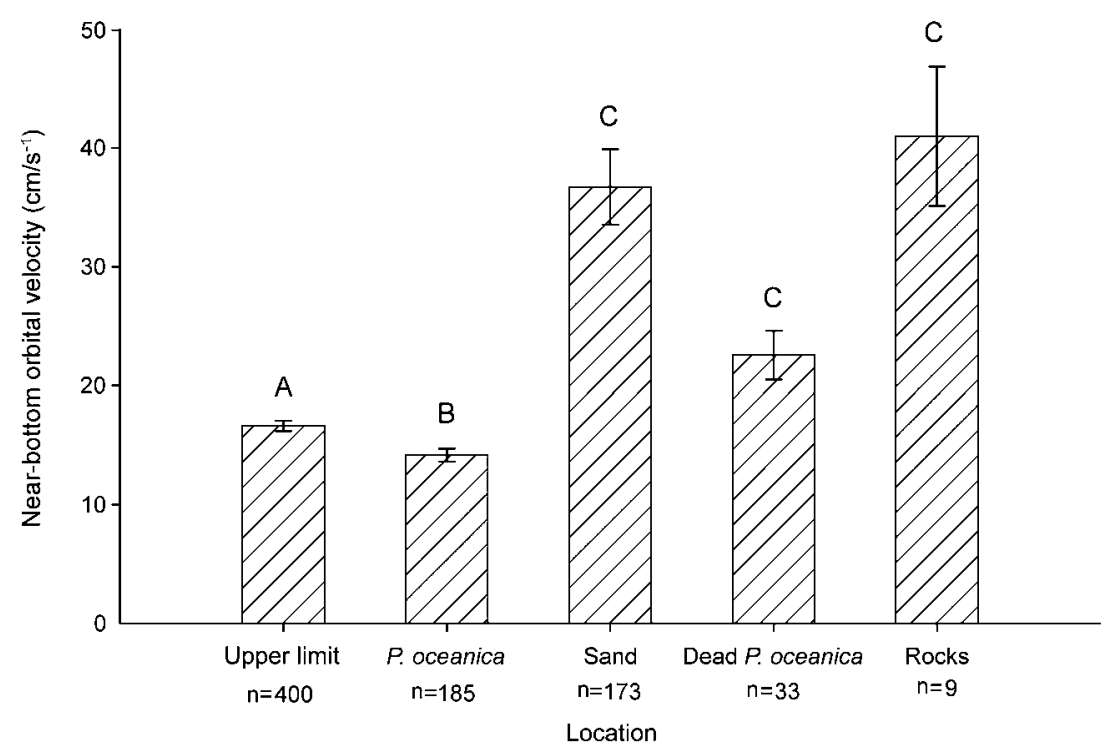

Figure 7 Mean near-bottom orbital velocity above each bottom type in Cala Millor (Majorca, Western Mediterranean Sea). Different capital letters indicate significant differences between bottom types (post hoc multiple pairwise comparison of mean ranks, $\mathrm{p}<0.05$ ). Error bars show $95 \%$ confidence intervals. $\mathrm{N}$ values indicate the number of points selected randomly in each bottom type. Differences in $\mathrm{N}$ values between bottom types are driven by the differences in percentage covers of each bottom type in the study area. P., Posidonia.

Frederiksen et al. (2004) used aerial photographs to follow changes in the distribution of Zostera marina from 1954 to 1999 and showed that seagrass landscapes can change extensively over long periods of time, especially in the more wave-exposed areas. Comparison of aerial photographs taken in 1956 and 2004 indicates that the upper depth limit of Posidonia oceanica in Cala Millor has regressed in the south part of the beach (IMEDEA 2005), which is a sector of the beach well exposed to the most energetic waves (those from the N-NNE). We do not rule out, however, that other processes may determine the upper depth limit of $P$. oceanica. This seagrass species is able to grow in certain locations, usually sheltered, almost to sea level (Ribera et al. 1997), which suggests that neither photo-inhibition nor temperature fluctuations associated with shallow depths are important in setting the upper depth limit. Except for the desiccation effects associated with exposure to air at low tides (negligible in the Mediterranean Sea), the consensus is that the upper depth limit of seagrasses is set by the energy of currents and waves (Koch et al. 2006). Wave breaking might have a role in establishing the upper limit, but the position at which waves break will change depending on wave height, wave period, and presence of submerged sandbars. In addition, the effect of waves of certain energy may depend on the amount of time the plants are exposed to different levels of wave energy. Average wave conditions have been used to estimate the average field of near-bottom orbital velocities, but other wave statistics could be used, such as extreme events (De Falco et al. 2008), and elaborate a prediction of those velocities that allow the long-term persistence of $P$. oceanica. We used 44 years of data, as this would be an adequate period of time over which to average the effects of waves on the slow-growing P. oceanica (Marbà and Duarte 1998).

We note that sediment density and grain size characteristics have not been considered in this study. These granulometric characteristics may play an important role in determining the location of seagrasses, because wave energy will move and resuspend the sediment, which might bury or erode a seagrass meadow. Differences in sediment characteristics between locations will then contribute to the variability of the estimate of the threshold wave energy that sets the upper depth limit of Posidonia oceanica.

We conclude that the methodology presented here is a useful tool to estimate wave energy on the bottom and to identify the level that sets the upper depth limit of Posidonia oceanica meadows. Our approach provides testable estimates of the threshold level of wave energy that allows this species to persist and indicates a research program to validate them. This study also highlights the importance of interdisciplinary and multidisciplinary research in ecological modeling and, in particular, the need for hydrodynamical studies to elucidate the distribution of seagrasses at shallow depths.

\section{Acknowledgements}

E. Infantes would like to thank the Spanish Ministerio de Educación y Ciencia (MEC) FPI scholarship program (BES-200612850) for financial support. Financial support from grants CTM2005-01434, CTM2006-12072/MAR, and the Integrated Coastal Zone Management (UGIZC) project are acknowledged. The authors would like to thank Puertos del Estado for the HIPOCAS dataset and Marta Fuster for assistance with the data.

\section{References}

Bell, S.S., B.D. Robbins and S.L. Jensen. 1999. Gap dynamics in a seagrass landscape. Ecosystems 2: 493-504.

Cañellas, B., A. Orfila, F.J. Méndez, M. Menéndez and J. Tintore. 2007. Application of POT model to estimate the extreme significant wave height levels around the Balearic Sea (Western Mediterranean). J. Coast. Res. 50: 329-333. 
Castillo, M.C., A. Baquerizo and M.A. Losada. 2005. Temporal and spatial statistical variability of the wave height in the surf zone. 29th International Conference on Coastal Engineering, Lisbon, Portugal, 2004: 997-1008.

Chivers, R., N. Emerson and D. Burns. 1990. New acoustic processing for underway surveying. Hydrogr. J. 56: 8-17.

Dean, R.G. and R.A. Dalrymple. 2002. Coastal processes with engineering applications. Cambridge University Press, Cambridge. pp. 475.

De Falco, G., M. Baroli, A. Cucco and S. Simeone. 2008. Intrabasinal conditions promoting the development of a biogenic carbonate sedimentary facies associated with the seagrass Posidonia oceanica. Continent. Shelf Res. 28: 797-812.

Dennison, W.C. 1987. Effects of light on seagrass photosynthesis, growth and depth distribution. Aquat. Bot. 27: 15-26.

Dennison, W.C. and R.S. Alberte. 1985. Role of daily light period in the depth distribution of Zostera marina (eelgrass). Mar. Ecol. Prog. Ser. 25: 51-61.

Duarte, C.M. 1991. Seagrass depth limits. Aquat. Bot. 40: 363-377.

Duarte, C.M., J. Terrados, N.S.R. Agawin, M.D. Fortes, S.S. Bach and W.J. Kenworthy. 1997. Response of a mixed Philippine seagrass meadow to experimental burial. Mar. Ecol. Prog. Ser. 147: 285-294.

Folkard, A.M. 2005. Hydrodynamics of model Posidonia oceanica patches in shallow water. Limnol. Oceanogr. 50: 1592-1600.

Fonseca, M.S. and J.S. Fisher. 1986. A comparison of canopy friction and sediment movement between 4 species of seagrass with reference to their ecology and restoration. Mar. Ecol. Prog. Ser. 29: 15-22.

Fonseca, M.S. and W.J. Kenworthy. 1987. Effects of current on photosynthesis and distribution of seagrasses. Aquat. Bot. 27: $59-78$

Fonseca, M.S. and J.A. Cahalan. 1992. A preliminary evaluation of wave attenuation by 4 species of seagrass. Est. Coast. Shelf Sci. 35: 565-576.

Fonseca, M.S. and S.S. Bell. 1998. Influence of physical settings on seagrass landscapes near Beaufort, North Carolina, USA. Mar. Ecol. Prog. Ser. 171: 109-121.

Fonseca, M.S., J.S. Fisher, J.C. Zieman and G.W. Thayer. 1982. Influence of the seagrass, Zostera marina L., on current flow. Est. Coast. Shelf Sci. 15: 351-364.

Fonseca, M.S., J.C. Zieman, G.W. Thayer and J.S. Fisher. 1983. The role of current velocity in structuring eelgrass (Zostera marina L.) meadows. Est. Coast. Shelf Sci. 17: 367-380.

Fonseca, M.S., P.E. Whitfield, N.M. Kelly and S.S. Bell. 2002. Modeling seagrass landscape pattern and associated ecological attributes. Ecol. Appl. 12: 218-237.

Fornes, A., G. Basterretxea, A. Orfila, A. Jordi, A. Álvarez and J. Tintore. 2006. Mapping Posidonia oceanica from IKONOS. J. Photogramm. Remote Sens. 60: 315-322.

Frederiksen, M., D. Krause-Jensen, M. Holmer and J.S. Laursen. 2004. Spatial and temporal variation in eelgrass (Zostera marina) landscapes: influence of physical setting. Aquat. Bot. 78: 147-165.

Gacia, E. and C.M. Duarte. 2001. Sediment retention by a Mediterranean Posidonia oceanica meadow: the balance between deposition and resuspension. Est. Coast. Shelf Sci. 52: $505-514$

Gambi, M.C., A.R.M. Nowell and P.A. Jumars. 1990. Flume observations on flow dynamics in Zostera marina (eelgrass) beds. Mar. Ecol. Prog. Ser. 61: 159-169.

GIOC. 2003. Spectral wave propagation model (Oluca-SP). State Coastal Office, Spanish Environmental Ministry and University of Cantabria, Santander. pp. 170 (in Spanish).

Gómez-Pujol, L., A. Orfila, B. Canellas, A. Alvarez-Ellacuria, F.J. Mendez, R. Medina, et al. 2007. Morphodynamic classification of sandy beaches in low energetic marine environment. Mar. Geol. 242: 235-246.
Greve, T. and D. Krause-Jensen. 2005. Predictive modelling of eelgrass (Zostera marina) depth limits. Mar. Biol. 146: 849-858.

Hine, A.C., M.W. Evans, R.A. Davis and D.F. Belknap. 1987. Depositional response to seagrass mortality along a low-energy, barrier-island coast: west-central Florida. J. Sediment. Petrol. 57: 431-439.

Hovel, K.A., C.R. Fonseca, D.L. Myer, W.J. Kenworthy and P.E. Whitfield. 2002. Effects of seagrass landscape structure, structural complexity and hydrodynamic regime on macrofaunal densities in North Carolina seagrass beds. Mar. Ecol. Prog. Ser. 243: 11-24.

IMEDEA. 2005. Variabilidad y dinámica sedimentaria de las playas de Cala Millor y Cala Sant Vicent. Volumen 1. Govern de les Illes Balears, Cala Millor. pp. 103.

Keddy, P.A. 1984. Quantifying a within-lake gradient of wave energy in Gillfillan Lake, Nova-Scotia. Can. J. Bot. 62: 301309.

Kenworthy, W.J. and M.S. Fonseca. 1996. Light requirements of seagrasses Halodule wrightii and Syringodium filiforme derived from the relationship between diffuse light attenuation and maximum depth distribution. Estuaries 19: 740-750.

Kirby, J.T. and R.A. Dalrymple. 1983. The propagation of weakly nonlinear waves in the presence of varying depth and currents. In: Proceedings of the XXth Congress I.A.H.R., Moscow 7, Moscow, September, 1983: 198-202.

Koch, E.W. and S. Beer. 1996. Tides, light and the distribution of Zostera marina in Long Island Sound, USA. Aquat. Bot. 53: 97-107.

Koch, E.W. and G. Gust. 1999. Water flow in tide- and wavedominated beds of the seagrass Thalassia testudinum. Mar. Ecol. Prog. Ser. 184: 63-72.

Koch, E.W., J.D. Ackerman, J. Verduin and M. van Keulen. 2006. Fluid dynamics in seagrass ecology - from molecules to ecosystems. In: (A.W.D. Larkum, R.J. Orth, C.M. Duarte, eds). Seagrasses: biology, ecology and conservation. Springer, Dordrecht. pp. 193-224.

Krause-Jensen, D., M.F. Pedersen and C. Jensen. 2003. Regulation of eelgrass (Zostera marina) cover along depth gradients in Danish coastal waters. Estuaries 26: 866-877.

Leriche, A., V. Pasqualini, C.F. Boudouresque, G. Bernard, P. Bonhomme, P. Clabaut, et al. 2006. Spatial, temporal and structural variations of a Posidonia oceanica seagrass meadow facing human activities. Aquat. Bot. 84: 287-293.

Marbà, N. and C.M. Duarte. 1998. Rhizome elongation and seagrass clonal growth. Mar. Ecol. Prog. Ser. 174: 269-280.

McKenzie, L.J., M.A. Finkbeine and H. Kirkman. 2001. Methods for mapping seagrass distribution. In: (F.T. Short and R.G. Coles, eds). Global seagrass research methods. Elsevier, Amsterdam. pp. 101-121.

Orfila, A., A. Jordi, G. Basterretxea, G. Vizoso, N. Marba, C.M. Duarte, et al. 2005. Residence time and Posidonia oceanica in Cabrera Archipelago National Park, Spain. Continent. Shelf Res. 25: 1339-1352.

Orlowski, A. 1984. Application of multiple echo energy measurements for evaluation of sea bottom type. Oceanologia 19: 61-78.

Pasqualini, V., C. Pergent-Martini, P. Clabaut and G. Pergent. 1998. Mapping of Posidonia oceanica using aerial photographs and side scan sonar: application off the Island of Corsica (France). Est. Coast. Shelf Sci. 47: 359-367.

Preen, A.R., W.J. Lee Long and R.G. Coles. 1995. Flood and cyclone related loss, and partial recovery, of more than 1000 $\mathrm{km}^{2}$ of seagrass in Hervey Bay, Queensland, Australia. Aquat. Bot. 52: 3-17.

Procaccini, G., M.C. Buia, M.C. Gambi, M. Perez, G. Pergent, C. Pergent-Martini and J. Romero. 2003. The seagrasses of the Western Mediterranean. In: (E.P. Green, F.T. Short, eds). World atlas of seagrasses, UNEP World Conservation Monitoring Centre. University of California Press, Berkeley, CA. pp. $48-58$. 
Ratsimandresy, A.W., M.G. Sotillo, J.C. Carretero Albiach, E. Álvarez Fanjul, H. Hajji. 2008. A 44-year high-resolution ocean and atmospheric hindcast for the Mediterranean Basin Developer within the HIPOCAS Project. Coast. Eng. 55: 825-826.

Ribera, G., M. Coloreu, C. Rodríguez-Prieto and E. Ballesteros. 1997. Phytobenthic assemblages of Addaia Bay (Menorca, Western Mediterranean): composition and distribution. Bot. Mar. 40: 523-532.

Robertson, A.I. and K.H. Mann. 1984. Disturbance by ice and life-history adaptations of the seagrass Zostera marina. Mar. Biol. 80: 131-141.

Shepherd, S.A. and H.B.S. Womersley. 1981. The algal and seagrass ecology of Waterloo Bay, South-Australia. Aquat. Bot. 11: 305-371.

Soares, C.G., J.C. Carretero, R. Weisse and E. Alvarez. 2002. A 40 years hindcast of wind, sea level and waves in European waters. In: Proceedings of OMAE 2002: 21st International Conference on Offshore Mechanics and Artic Engineering, Oslo, Norway 2000: 1-7.

Terrados, J. and C.M. Duarte. 2000. Experimental evidence of reduced particle resuspension within a seagrass (Posidonia oceanica) meadow. J. Exp. Mar. Biol. Ecol. 243: 45-53.

van Katwijk, M.M. and D.C.R. Hermus. 2000. Effects of water dynamics on Zostera marina: transplantation experiments in the intertidal Dutch Wadden Sea. Mar. Ecol. Prog. Ser. 208: 107-118.

van Katwijk, M.M., D.C.R. Hermus, D.J. de Jong, R.M. Asmus and V.N. de Jonge. 2000. Habitat suitability of the Wadden Sea for restoration of Zostera marina beds. Helgol. Mar. Res. 54: 117-128.

Williams, S.L. 1988. Disturbance and recovery of a deep-water Caribbean seagrass bed. Mar. Ecol. Prog. Ser. 42: 63-71.

Worcester, S.E. 1995. Effects of eelgrass beds on advection and turbulent mixing in low current and low shoot density environments. Mar. Ecol. Prog. Ser. 126: 223-232.

Wright, L.D. and A.D. Short. 1983. Morphodynamics of beaches and surf zones in Australia. In: (P.D. Koma, ed). Handbook of coastal processes and erosion. CRC Press, Boca Raton, FL. pp. 35-64.

Received 26 February, 2008; accepted 23 September, 2008; online first 13 February, 2009 